\title{
Pattern of Acute Organophosphorus Poisoning at a Tertiary Care Hospital of Western Maharashtra
}

\author{
Dr. Sandeep Sitaram Kadu1 Dr. Shamkumar U. Burungale ${ }^{2}$, Amrut Arun Swami ${ }^{3}$
}

\begin{abstract}
${ }^{1}$ Professor \& Head, Department of Forensic Medicine, DVVPF's Medical College, Ahmednagar, Maharashtra, India ${ }^{2}$ Associate Professor, Department of Community Medicine, DVVPF's Medical College, Ahmednagar, Maharashtra, India

${ }^{3}$ Assistant Professor, Department of Community Medicine, DVVPF's Medical College, Ahmednagar, Maharashtra, India
\end{abstract}

\begin{abstract}
Background: Every year, 3 million cases of pesticide, mainly O.P. poisoning, occurs all over the world. Therefore, statistics regarding O.P. poisoning in a specific region will aid in the early diagnosis and treatment of cases. The main objective of this research project is to find out the pattern of O.P. poisoning cases at the tertiary care center. Methods: We conducted a retrospective cross-sectional study, in which we analyzed data from 40 cases of O.P. poisoning, including patient information regarding gender, age, time of ingestion, type of poison, mode of poisoning, any first aid received, treatment given, duration of hospital stay and outcome of the treatment. Results: There were 16 females (40\%) and 24 males $(60 \%)$. The most common age group was 21 to 40 years, with 19 participants $(47.50 \%)$. The majority of the participants were from the rural area, 38 cases (95\%), while in 36 cases, the poisoning was suicidal $(90 \%) .28$ participants $(70 \%)$ received some form of first aid. In addition, 21 of the participants received Atropine (52.50\%), 13 received only gastric lavage (32.50\%), 5 received both Atropine and Pralidoxime (12.50\%), while one patient only received Pralidoxime $(2.5 \%)$ as treatment. I.C.U. admission was required in 39 participants $(97.50 \%)$, and ventilatory support was required in 2 participants (5\%). Our study observed 4 deaths $(10 \%)$ amongst our participants. The multivariate analysis of deaths in our study showed that specifically not receiving any first aid $(p=0.039)$ and requirement of the ventilator $(p<0.001)$ were seen to have a significant association with deaths in our study. Conclusion: O.P. poisoning is the commonest cause of suicidal deaths in developing countries. Creating awareness regarding O.P. poisoning and legislative action on using hazardous poisons will help reduce the deaths.
\end{abstract}

KEYWORDS: O.P. Poisoning, Farmers, Suicide, First Aid.

\section{INTRODUCTION}

$\mathrm{P}$ oison is any substance that causes dangerous effects on humans and animals after ingestion, inhalation, and injection in the body [1]. Poison act as a silent weapon because it can be easily used without causing any suspicion. Organophosphorus poisoning is a global health problem. According to the World Health Organization (WHO) statistics, every year, 3 million cases of pesticide, mainly O.P. poisoning, occur all over the world [2]. Out of these cases, 2 million are suicidal, and 1 million are accidental. India is well known for its economic dependency on agricultural production. Organophosphorus poisoning is the most common mode of poisoning in India [3]. It is readily available as well as accessible poison in rural populations. In India, the suicidal mode of death occurs poisoning. As per government records, 23,172 per year suicidal deaths occur in our country, but the actual number could be three times more than recorded cases. If suicidal and accidental pesticide poisoning cases are added, the figure reaches up to 80,000 deaths per year [4] For dealing with pesticide poisoning, WHO suggested banning the highly hazardous pesticides. Research has proved that after banning hazardous pesticides, there is

Correspondence: Dr Shamkumar, Associate Professor, Department of Community Medicine, DVVPF's Medical College, Ahmednagar, Maharashtra, India Email: drburungale@gmail.com

\begin{tabular}{|l|} 
\\
\end{tabular}


a drastic reduction in pesticide poisoning cases. It is also an occupational hazard [5]. Chronic exposure to pesticides has led to health problems related to respiratory, neurological, and cancer disorders [6].

Statistics regarding organophosphorus poisoning in a specific region will aid in the early diagnosis and treatment of cases and help reduce the mortality and morbidity rates. The main objective of this research project is to find out the pattern of O.P. poisoning cases at the tertiary care center, Dr. Vithalrao Vikhe Patil Foundation's Medical College and hospital, Ahmednagar, which is one of the largest districts of Maharashtra state. Our institution has taken responsibility for the families of the victims. We provide free medical treatment for these patients; also, we provide free education, job opportunities, and financial aid to the dependent family members.

\section{Material And Methodology}

Study design: This study is a retrospective cross-sectional study

Study location: Dr. Vithalrao Vikhe Patil Foundation's Medical College and hospital, Ahmednagar, Maharashtra.

Study period: The study period is from Jan 2019 up to Dec 2020.

Ethics approval: The institutional ethics committee approved the study

Inclusion criteria: This study includes all O.P. poisoning cases admitted and treated in our hospital

Exclusion criteria: In complete case sheets

Sample size: Fourty

Methodology: Data was collected from the Indoor patient files of O.P. cases on validated case record forms. In the case record form, the patient information regarding gender, age, time of ingestion, type of poison, mode of poisoning, any first aid received, treatment given, duration of hospital stay, and treatment outcome were recorded. The data was collected using a predesigned semi-structured questionnaire.

Statistical analysis: Data were entered in Microsoft excel 2013, and this collected data is analyzed using SPSS 20.

\section{RESUlts}

There were 16 females (40\%) and 24 males (60\%) in our study. Thus, the male-to-female ratio was 1.5: 1 . The most common age group was 21 to 40 years with 19 participants $(47.50 \%)$ followed by 10 people with age less than 20 years $(25 \%)$, 9 people with age 41 to 60 years $(22.5 \%)$, and 2 people had aged more than 60 years (5\%). [Fig 1]

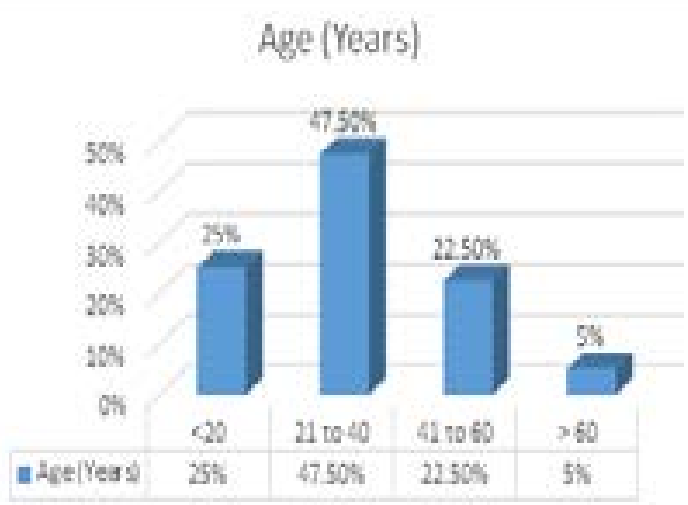

\section{Fig 1. Distribution of the study participants according to Age Group}

The majority of the participants were from the rural area, 38 cases (95\%), while 2 were from the urban area $(5 \%)$. We observed that the reason for consumption of poison in 36 cases was suicidal $(90 \%)$, in 3 cases, it was accidental $(7.5 \%)$, and in 1 case, it was homicidal (2.5\%). [Fig 2]

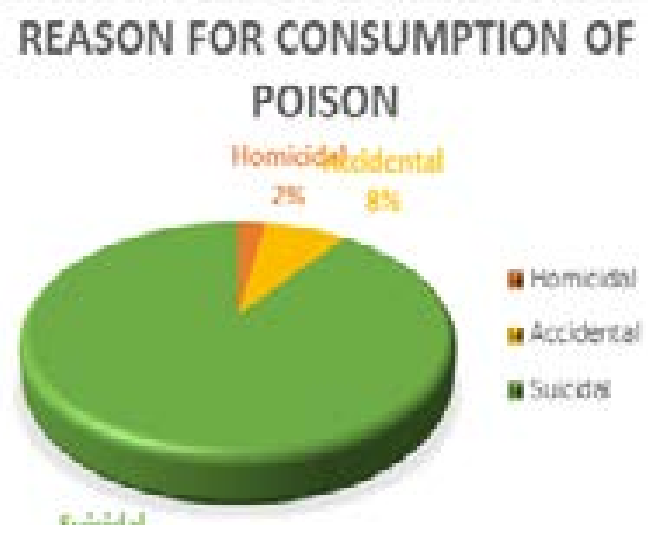

\section{Fig 2. Reason for consumption of Poison}

Our study observed that 28 participants $(70 \%)$ received first aid at the primary level before getting admitted to the hospital, while 12 cases $(30 \%)$ did not receive any first aid.

Table 1. Distribution of the study participants according to treatment given

\begin{tabular}{|c|c|c|}
\hline Treatment Given & Frequency & Percentage \\
\hline Atropine & 21 & 52.5 \\
\hline Pralidoxime & 1 & 2.5 \\
\hline $\begin{array}{c}\text { Atropine and } \\
\text { Pralidoxime }\end{array}$ & 5 & 12.5 \\
\hline $\begin{array}{c}\text { Only Gastric } \\
\text { Lavage }\end{array}$ & 13 & 32.5 \\
\hline
\end{tabular}

21 of the participants received Atropine (52.50\%), 13 received only gastric lavage $(32.50 \%)$, 5 received both Atropine and Pralidoxime $(12.50 \%)$, while one patient only received Pralidoxime $(2.5 \%)$ as treatment [Table 1]. I.C.U. 
Admission was required in 39 participants $(97.50 \%)$, and ventilatory support was required in 2 participants $(5 \%)$.

Table 2. Distribution of the study participants according to a hospital stay in Days

\begin{tabular}{|c|c|c|}
\hline Hospital Stay & Frequency & Percentage \\
\hline$\leq 2$ Days & 15 & 37.5 \\
\hline 3 to 5 Days & 20 & 50 \\
\hline > 5 Days & 5 & 12.5 \\
\hline
\end{tabular}

We saw that majority of the participants, 20 required 3 to 5 days hospital stay $(50 \%)$ while 15 were discharged in less than or equal to 2 days $(37.50 \%)$, and 5 were discharged after more than 5 days $(12.50 \%)$, the mean duration of hospital stay was $4.2 \pm 3.9$ days, range of hospital stay was 1 to 12 days [Table 2]. Our study observed 4 deaths (10\%) amongst our participants, while 36 recovered and discharged from the hospital (90\%) [Fig 3].

\section{Outcome}

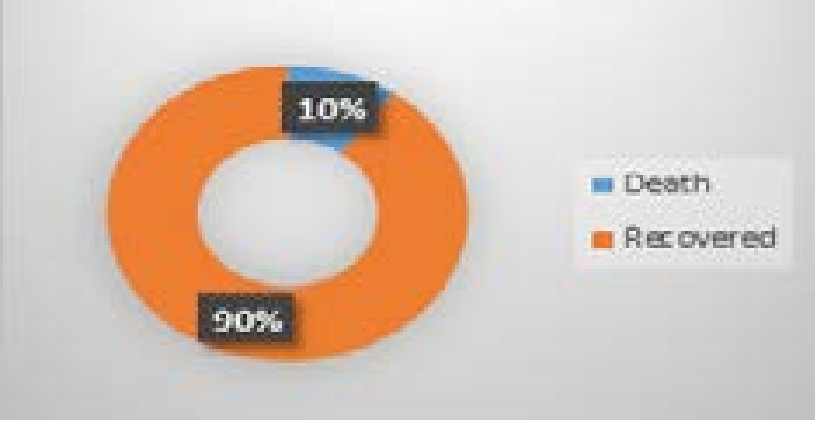

Fig 3. Distribution of the study participants according to Outcome

We observed that out of the 4 deaths, all were males from the rural area and took poison for suicidal purposes; all required I.C.U admission and 2 required ventilatory support. 2 patients died within 24 hours of admission, while one died on the 2nd day, and one patient died on the 4th day of admission.

\section{Table 3. Multivariate analysis for deaths}

\begin{tabular}{|l|l|l|}
\hline Study Parameter & F Value & P value \\
\hline Age & 2.24 & 0.142 \\
\hline Sex Male & 3.04 & 0.089 \\
\hline Reason Suicide & 0.47 & 0.495 \\
\hline No any First aid & 4.56 & 0.039 \\
\hline Ventilator Required & 34.2 & $<0.001$ \\
\hline $\begin{array}{l}\text { Number of days in the } \\
\text { hospital }\end{array}$ & 1.95 & 0.171 \\
\hline \multicolumn{3}{|c|}{$\mathrm{F}=8.37, \mathrm{p}<0.001$} \\
\hline
\end{tabular}

The multivariate analysis of deaths in our study had a significant association for age, male gender, suicide as a reason for poisoning, not receiving any first aid, a requirement of the ventilator, and less duration of stay in hospital. $(p<0.001)$. Specifically, not receiving any first aid $(p=0.039)$ and requirement of the ventilator $(p<0.001)$ were seen to have a significant association with deaths in our study.

\section{Discussion}

According to W.H.O., thirty lakh acute poisoning cases with more than 2 lakh deaths occur annually. Of these, almost $90 \%$ of fatal poisoning occurs in developing countries, particularly among farmers and farm-related workers [7]. More than 50,000 people die every year from toxic exposure in India [8].

We observed 16 females (40\%) and 24 males $(60 \%)$ in our study. Therefore, the male-tofemale ratio was 1.5: 1 . However, in a study by P Gupta et al. [9], the Male: Female ratio was 1.3:1 (57.58\% Males and $42.42 \%$ Females). J Gargi et al.[10] observed a male majority with the male to female ratio of $3: 1$; most of the cases in their study were in the age group of $21-30$ years $(45.59 \%)$.

In our study, the most common age group was 21 to 40 years with 19 participants $(47.5 \%)$, followed by 10 people with age less than 20 years $(25 \%), 9$ people with age 41 to 60 years $(22.5 \%)$, and 2 people had aged more than 60 years $(5 \%)$. Similar findings were given by P Gupta et al. 9, who reported most cases from the age group of 21-30 years (39.09\%). P Ali et al.[11] also found that most of the cases were young adult people from 16- 40 years (about 80\%). It may be that this age group is the productive age group, and they have to face all kinds of struggles in their life.

The majority of the participants were from the rural area, 38 cases (95\%), while 2 were from the urban area $(5 \%)$. The majority of the cases were either farmers or farm laborers in our study, 37 $(92.5 \%)$, while the rest 3 were students $(7.5 \%)$ as our study has been conducted in a rural-based tertiary care center. Tandle RM et al.[12] found that most of the participants were from rural areas, $74.71 \%$.

We observed that the reason for consumption of poison in 36 cases was suicidal (90\%), in 3 cases, it was accidental $(7.5 \%)$, and in 1 case, it was homicidal $(2.5 \%)$. P Ali et al. 11 also found the primary reason as suicidal in $65 \%$ of the cases, followed by accidental $(27 \%)$ and homicidal $(8 \%)$.

Our study observed that 28 participants $(70 \%)$ received first aid at the primary level before getting admitted to the hospital, while 12 cases

Int. j. clin. biomed. res. 2021;7(2):23-27 
(30\%) did not receive any first aid.

Kumar MR et al.[13], in their study, found that $45.5 \%$ of patients received some form of first aid before getting admitted to the hospital. On the other hand, in a study by P Gupta et al. 9, Gastric lavage was performed as the first line of management in emergency for the majority of the patients. 21 of the participants received Atropine $(52.50 \%), 13$ received only gastric lavage $(32.50 \%), 5$ received both Atropine and Pralidoxime (12.50\%). In comparison, one patient only received Pralidoxime (2.5\%) as treatment.

I.C.U admission was required in 39 participants $(97.50 \%)$, and ventilatory support was required in 2 participants $(5 \%)$.

Maximum cases had received the treatment within 4-8 hours of ingestion or exposure to poisonous substances. This trend is due to delay in transport, time consumed in referral, remote areas of an incident. The importance of receiving first aid and gastric lavage is that it will help reduce further complications and mortality in the patients.

We saw that majority of the participants, 20 required 3 to 5 days hospital stay (50\%) while 15 were discharged in less than or equal to 2 days $(37.50 \%)$, and 5 were discharged after more than 5 days $(12.50 \%)$, the mean duration of hospital stay was $4.2 \pm 3.9$ days, range of hospital stay was 1 to 12 days. P Ali et al.[11] also found the most common hospital stay was 3-4 days in 56\% of the participants. On the other hand, Kumar MR et al.[13], in their study, found that mean hospital stay was $7.5 \pm 4.7$ days (range 1-26 days).

Our study observed 4 deaths (10\%) amongst our participants, while 36 patients recovered and were discharged from the hospital (90\%). Kumar MR et al.[13], in their study, observed mortality of $9.9 \%$, similar to our study.

We observed that out of the 4 deaths, all were males from the rural area and took poison for suicidal purposes; all required I.C.U. Admission and 2 required ventilatory support. 2 patients died within 24 hours of admission, while one died on the 2nd day, and one patient died on the 4th day of admission.

The multivariate analysis of deaths in our study had a significant association for age, male gender, suicide as a reason for poisoning, not receiving any first aid, a requirement of a ventilator, and duration of stay in hospital. $(p<0.001)$

Specifically, not receiving any first aid $(p=0.039)$ and the requirement of a ventilator $(p<0.001)$ were seen to have a significant association with deaths in our study. In addition, Ali et al. [11] found a significant association between the cases that required ventilatory support and death.

\section{Conclusion}

O.P. poisoning is the commonest cause of suicidal deaths in developing countries. The reason behind this is the easy availability and accessibility of pesticides. To deal with this problem, the government should consider banning highly hazardous pesticides. Accidental poisonings occur due to a lack of awareness to use P.P.E. kits while spraying the pesticides by the farmers. Proper training and awareness about the use of P.P.E. kits can reduce accidental deaths in these cases. Training about first aid of the poisoning cases at P.H.C. and sub Centre level to A.N.M.s, Health workers, Anganwadi workers, and ASHAs can help in reducing morbidity and mortality. As farmers face many problems due to natural calamities and financial burdens, proper counseling and financial support at a specific time to the farmers can reduce the suicidal incidences.

Conflict of interest : Nil Source of funding : Nil

\section{REFERENCES}

1. Guitart R, Giménez N. What is a" poison"? Proposal of definition. Medicina clinica. 2011 Mar 31;138(3):127-32

2. World Health Organization. The impact of pesticides on health. Downloaded from: http://www.who.int/mental_health / prevention/suicide/en/PesticidesHealth2. pdf .

3. Vaidya YP, Hulke SM. Study of trends of poisoning in the cases reported to government hospital, Yavatmal. Chronicles of Young Scientists. 2012;3(1):1

4. Madhavan I, Zachariah A, Utyasheva L, Sethi A. The 2020 Indian government's pesticide ban is a timely policy move to safeguard the health and lives of Indian citizens.

5. Bonvoisin T, Utyasheva L, Knipe D, Gunnell D, Eddleston M. Suicide by pesticide poisoning in India: a review of pesticide regulations and their impact on suicide trends. B.M.C. public health. 2020;20(1):1-6

6. Sabarwal A, Kumar K, Singh RP. Hazardous effects of chemical pesticides on human health-Cancer and other associated disorders. Environmental toxicology and pharmacology. 2018;63:103-14

7. Reddy KSN. The Essentials of Forensic Medicine and Toxicology. 31st ed. India: K Suguna Devi, 2012:467

8. Pillay VV. Textbook of Forensic Medicine and Toxicology. 16th ed. India: Paras. 2011; P-

Int. j. clin. biomed. res. 2021;7(2):23-27 
402-4.

9. Gupta P, Kumar A, Singh SP, Prakash M, Gupta M, Kumar P. Pattern of cases of acute poisoning in a rural tertiary care center in northern India. National Journal of Community Medicine. 2016;7(4):307-10

10. Gargi J, Rai H, Chanana A, Raj G, Sharma G, Bagga IJS. Current Trends of Poisoning. A Hospital Profile, J Indian Med Assoc. 2006; 104(2):72-3

11. Ali P, Anwer A, Bashir B, Jabeen R, Haroon $\mathrm{H}$, Makki K. Clinical pattern and outcome of organophosphorus poisoning. J Liaq Uni
Med Health Sci. 2012;11(1):15-8.

12. Tandle RM, Kadu SS. Study of Pattern of Acute Poisoning Cases in Females at a Rural Tertiary Care Hospital in Ahmednagar, Maharashtra, India. Suicide. 2016;56:64-36

13. Kumar MR, Kumar GV, Babu PR, Kumar SS, Subrahmanyam BV, Veeraprasad M, Rammohan P, Srinivas M, Agrawal A. A retrospective analysis of acute organophosphorus poisoning cases admitted to the tertiary care teaching hospital in South India. Annals of African medicine. 2014;13(2):71-5 